\title{
Problem-Based Learning and e-Learning in Sound Recording
}

\author{
Michele Della Ventura
}

\begin{abstract}
In the teaching of sound recording, the problem of each school is how to present course material so that students not only gain knowledge of the discipline, but also become self-directed learners who develop problem-solving skills they can apply in future courses and in their careers. In Problem-Based Learning (PBL) courses, students work with classmates to solve complex and authentic problems that help develop content knowledge as well as problem-solving, reasoning, communication, and self-assessment skills.

The aim of this paper is to describe and discuss the applicability of PBL and E-learning in Music Technology in the High School. The result of implementing PBL in an e-learning environment was evaluated using a methodological tool based on surveys, filled by the students at the end of the courses. The results were compared to the other courses based on more passive-learning methods, and on this background some future initiatives to be taken were proposed.
\end{abstract}

Index Terms-E-learning, experience, learning process, music technology, problem based learning, sound recording.

\section{INTRODUCTION}

The introduction of e-learning represents a significant change in practice that really needs to be managed carefully, and there are a number of important components at different levels that require alignment through the process of change management [1].

The integration of ICT (Information and Communication Technology) into education leads to major changes in the class of students: they become the essential element of the teaching/learning process, participating actively in this process and turning into self-taught people, with the aim of achieving their full education from a cognitive, social, physical and emotional viewpoint.

Thus, the classes become more attractive for students, the teaching method is more flexible and the teacher's adaptability to the pupils' requirements is improved [2]. The benefits of using ICT in the educational process reside both in the manifold instruction opportunities it offers and in the transformation of relationships among learners, teachers and the learning equipment.

Important to note is the fact that emphasis is now increasingly placed on the process rather than the content of education [3]: the teachers must understand the strengths and weakness of new technologies and implementation issues

Manuscript received September 25, 2013; revised December 17, 2013. This work was supported in part by the U.S. Department of Commerce under Grant BS123456 (sponsor and financial support acknowledgment goes here).

Della Ventura Michele is with the Music Academy "Studio Musica" department of Technology, 31100 Treviso, Italy (e-mail: michele.dellaventura@tin.it). such as overcoming users' resistance to change. This paradigm shift has been occasioned by an explosion of knowledge, and rapid innovations in technology. In this regard, e-Learning is central to the educational sector. Such an educational environment has given rise to a redefined setting for learning and teaching, thus changing the future principles, practices, policies and the underlying issues related to knowledge acquisition that define the value, worth, meaning and delivery of educational services [4].

This article will present a method, based on blended learning and PBL, used in the Music School, to convey information about the Sound Recording. The main aim is to assist students to construct knowledge and develop skills in problem solving, communication, cooperation, negotiation, and decision making.

This paper is organized as follows. Section II describes the sound recording. Section III describes the Problem-Based Learning. Section IV shows the results and discussion. Finally, conclusions are drawn in Section V.

\section{SOUND RECORDING AND EXPERIENCE}

Modern audio equipment allows effective recordings to be made without necessarily requiring any in-depth understanding of the physical principles and technical concepts involved. However, understanding the desired qualities of the end product and how these can best be achieved by taking into account the acoustical characteristics of the sources, the acoustic spaces in which they are recorded, and the capabilities and limitations of the equipment (Fig. 1), ensures that the user is fully aware of all technical possibilities and thereby increases the chances of successfully obtaining higher quality recordings or recordings which more closely approach to desired characteristics [5].

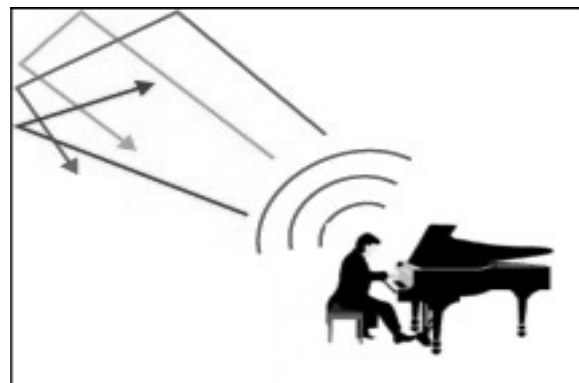

Fig. 1. Example of reflection of sound waves in a concert room: this is one of the problems in a sound recording. How is possible to deal with this problem?

Capturing the natural timbre and the full dynamics of a music instrument requires both skill and quality recording equipment. 
Factors influencing the sound recording are [6], [7]:

The type of musical instrument and the position in the room;

The room acoustics in which the musical instruments is placed;

The repertoire to be played: classical music deserves a natural blend of ambience, but different composers all have their own characteristics, which leave more or less space for the ambience to influence the music. Rhythmic music and jazz traditionally are played in different types of locations. Therefore, the listener's expectations of the timbre and ambiance are somewhat different;

The choice of microphone;

The choice of the microphone techniques: there exist a number of well-developed microphone techniques used for making musical, film, or voice sources. For instance, the choice of a technique depends on a number of factors, including:

the collection of extraneous noise: this can be a concern, especially in amplified performances, where audio feedback can be a significant problem; alternatively, it can be a desired outcome, in situations where ambient noise is useful (hall reverberation, audience reaction);

Choice of a signal type: Mono, stereo or multi-channel;

Type of sound-source (Acoustic instruments produce a sound very different from electric instruments, which are again different from the human voice);

Situational circumstances: sometimes a microphone should not be visible, or having a microphone nearby is not appropriate;

Processing: if the signal is destined to be heavily processed, or "mixed down", a different type of input may be required;

In a sound recording, the main problem is to consider all these factors together, to find an optimal solution. In this regard, one of the main elements to take into account is the "experience" [7].

The student solves unfamiliar problems slowly, but recognizes and quickly solves problems that are similar to those they have solved before [8]: the student remember problems that they have solved, thereby improving their performance on similar problems in the future. In this way, the student also learns from successes as well as from mistakes.

A further opportunity to learn occurs when student consult with other students [9]. Learning from collective experience is not about getting people to have the same experience; it actually begins with understanding and acknowledging the variety of experiences taking place among the people involved [10].

Ultimately, often is possible to do a prior study to identify the problem and the solution, and in this stage the consultation of other people (students, teachers ...) could be important.

For this reason, PBL become a good solution to share students' experiences in order to identify and solve a problem in a sound recording.

\section{Problem-BASEd Learning}

Problem-Based Learning (PBL) is a learning environment which has been defined by several authors and in a wide sense form of PBL that have been used includes research, case studies and guided design [7].

According to Barrows and Kelson [11] PBL is both a curriculum and a process. The curriculum consists of carefully selected and designed problems that demand from the learner acquisition of critical knowledge, problem solving proficiency, self-directed learning strategies, and team participation skills. The process replicates the commonly used systemic approach to resolving problems or meeting challenges that are encountered in life and career. It does provide the ability for students to be immersed into pseudo-real world scenarios, thus encouraging them to take more responsibility for their own learning and apply their knowledge at successively higher levels [12].

In short, PBL is a cyclic process which comprises 3 phases [13]:

1) Cooperative thinking about the initial problem and identification of learning needs,

2) Individual self-guided study about the learning tasks,

3) Application of new acquired knowledge to the problem in a cooperative way and synthesis of their learning.

PBL is an effective method for improving students' problem-solving skills. Students will make strong connections between concepts when they learn facts and skills by actively working with information rather than by passively receiving information [14].

The concept of a problem is central to PBL.

A critical question in the course of implementing PBL is: what is a problem? A problem in PBL is an incentive for students [15], a challenge to start them off on their learning process.

A good PBL problem has the following characteristics [16]:

- is engaging and oriented to the real-world;

- is structured and complex;

- generates multiple hypotheses;

- requires team effort;

- is consistent with desired learning outcomes;

- builds upon previous knowledge/experiences;

- promotes development of higher order cognitive skills.

The selection of problems is critical for the success of the course: a problem as incentive for the learning processes is a central principle to enhance students' motivation [17], [18], therefore, it is important which problems the students are attracted to on the basis of their own experiences and interests.

\section{RESUlTS AND DisCUSSION}

The method proposed in this article consists in the use of the computer environment Moodle (Modular Object-Oriented Dynamic Learning Environment), an open source e-learning platform. Moodle is modular in construction and can be extended to create activity modules.

The Sound Recording course was organized in twelve weeks, so that lectures and practical materials for the tasks were available. Moreover, a forum was created, as well as a calendar which reflected the main activities.

The result of implementing PBL in an e-learning 
environment was evaluated using a methodological tool based on surveys, filled by the students at the end of the courses.

PBL was evaluated using four different surveys about:

1) generalization: future applicability, other areas connection, continuing with the method, possible generalization to other courses, effects on the institution, environment;

2) learning effects: acquired skills, i.e. written/oral expression, group work, decision making, critical thinking, self-confidence, learning to learn, management, languages;

3) actual implementation: information about time, effort, dedication, work, required by this approach, and characteristics and criteria for implementation/evaluation;

4) emotional component: satisfaction, expectations, attitudes, motivation, environment.

From the survey emerge the following results.

At the beginning (first four weeks), students did not find differences between the traditional course and the e-learning course (see Fig. 2): in their opinion PBL did not involve any advantage, but also any drawback. Moreover, students found that PBL requires more time, resources and effort.

After, students find PBL more interesting, challenging and enjoyable, as well as it allows self-directed learning and makes them be proud of their work (see Fig. 2).

Other aspects considered as very positive by the student regarding PBL were: cooperative work, utilization of real problems, active participation, transversal skills integration and better self-knowledge. Students are more satisfied and are more positive regarding their learning, while students in the traditional curriculum often tend to evaluate their experience as irrelevant, passive and boring.

Moreover, students had an attitude significantly more positive to PBL than to the traditional approach, and recommend it implementation in other areas.

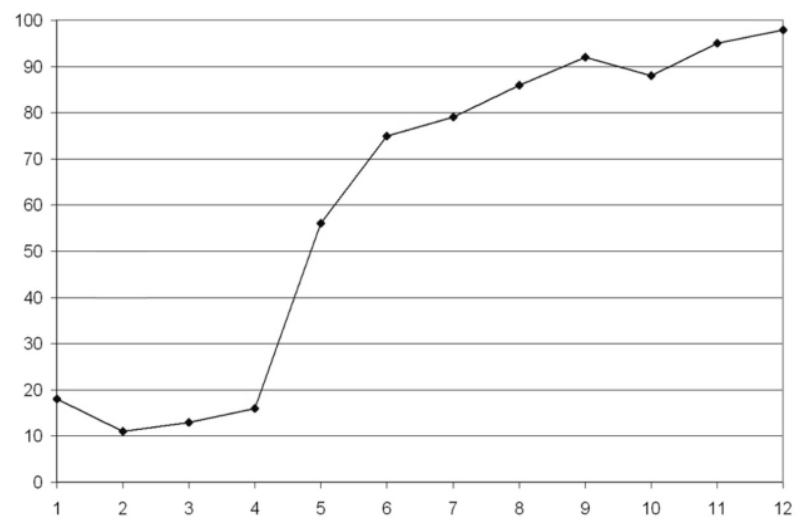

Fig. 2. Percentage of students (y-axis) involved during the twelve weeks (x-axis) of the course of sound recording.

Teachers interpreted the above mentioned findings as the result of gradual introduction of computers into the music instruction and from the point of view of development as a result of adequate planning of learning.

Learning motivation (for music) can be significantly different in reference to learning environment since it may be influenced by individually conditioned factors of relationships between teaching and learning environment.
Someone may love singing and playing the instruments, but have no interest to work on computer and vice versa. On the contrary, students with less developed performance skills can much more easily articulate their musical abilities with the help of modern technology. This might be an important element to encourage learning interest.

From the notes of teachers' reflections we found out that there was a positive productive students' motivation which was expressed in their selection of more demanding tasks and in their perseverance in improving achievements and their desire to put in place new musical ideas.

In general, students estimated that computer aided learning is much more fun and relaxing, than "classical learning" in the classroom.

\section{CONClusions}

The method presented in this article represent a means of support for the sound recording within the field of Music Education, one domain that has traditionally taken place in a face-to-face mode.

E-Learning has had an enormous impact on higher education yet there has been only limited application of E-Learning to Music Education. Many teachers consider the E-learning impossible to use with own musical discipline: the main problem is, that they don't know this new instrument and its potentialities.

This study, therefore, presents the criticalities concerning the sound recording and tries to surpass these through the sharing of the students' experiences, using the PBL method.

$\mathrm{PBL}$ is an instructional method where students "learn to learn", working cooperatively in groups to seek solutions to real world problems. Group learning facilitates not only the acquisition of knowledge but also several other desirable attributes, such as communication skills, teamwork, problem solving, independent responsibility for learning, sharing information, and respect for others.

The PBL and e-learning implementation had reported successful results according to student's opinions. They improve significantly their analytical and transversal skills and competences, and become experienced in applying the theoretical elements from the lectures in practical problem solving.

Further research needs to assess the impact of variations in the practice of sound recording, and the type of technology used on the usefulness of recorded lectures. It may be the case that, depending of the discipline, the use of audio recordings of lectures finds a place as a means by which core information can be effectively made available to students, leaving more flexibility for the 'live' lecture to focus on other areas of student engagement, such as application or problem-focused methods of delivery.

\section{REFERENCES}

[1] V. Kumpikaite and R. Ciarnienè, "New training technologies and their use in training and development activities: Survey evidence from Lithuania," Journal of Business Economics and Management, 2008.

[2] N. Nedelcut, "Exploring the On-line Learning Means to Music Education," Prelude Platform Case Study, New York, 2009.

[3] R. E. Slavin, Educational Psychology: Theory and practice, Needham Heights, MA: Allyn and Bacon, 2000. 
[4] C. Stary and G. Weichhart, "An e-learning approach to informed problem solving," An International Journal of Knowledge Management \& E-Learning, vol. 4, no. 2, pp. 195-216, 2012.

[5] D. Woods. (1996). Problem-based Learning: Helping Your Students Gain the Most from PBL. [Online]. Available: http://chemeng.mcmaster.ca/pbl/pbl.htm

[6] D. M. Huber and R. E. Runstein, Modern Recording Techniques, Hoepli, 2005

[7] M. D. Ventura, Teoria e pratica della ripresa stereofonica, ABEditore, Milano, 2012.

[8] M. Haverilla, "E-learning experience and Perceived Learning Outcomes in an Undergraduate E-learning course," MERLOT Journal of Online Learning and Teaching, vol. 7, no. 2, 2011.

[9] B. A. Digolo, E. A. Andang'o, and J. Katuli, "E-learning as a strategy for enhancing access to music education," International Journal of Nusiness and Social Science, vol. 2, no. 11, pp. 135-139, 2011.

[10] G. R. Bushe, "Learning from Collective Experience," OD Practitioner, vol. 41, no. 3, pp. 19-23, 2009

[11] H. Barrows and A. Kelson. (2006). PBL overview. [Online]. Available: http://www.mcli.dist.maricopa.edu/pbl/info.htm,

[12] I. Denayer, K. Thaels, J. V. Sloten, and R. Gobin, "Teaching a structured approach to the design process for undergraduate engineering students by problem-based education," European Journal of Engineering Education, no. 28, pp. 203-214, 2003.

[13] J. C. Perrenet, "The Suitability of Problem-based Learning for Engineering Education: Theory and Practice," Teaching in Higher Education, no. 5, pp. 345-358, 2000.

[14] S. A. Gallagher, "Problem-based learning: Where did it come from, what does it do, and where is it going?" Journal for the Education of the Gifted, no. 20, pp. 332-362, 1997.

[15] G. R. Norman, "Problem-solving skills, Solving problems and problem-based learning," Medical Education, no. 22, pp. 279-286, 1986.

[16] B. S. Bloom, "Taxonomi of Educational Objectives," The Classification of Educational Goals, New York: David Mckay Company, 1956
[17] P. R. Pintrich and D. H. Schunk, Motivation in education: Theory, research, and appli cations, Columbus, OH: Merrill. Pribbenow, 2000.

[18] B. W. Tuckman, "The effect of learning and motivation strategies training on college students' achievement," Journal of College Student Development, no. 44, pp. 430-37, 2003

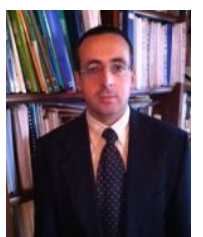

Michele Della Ventura defined his professional training, since high school, within the framework of two distinct areas of study: music and mathematics. He embarked on a course of study of the Pianoforte under the guidance of Donato Cuzzato, continuing then with Francesco Bencivenga under the guidance of whom he brilliantly graduated from the "A. Steffani" Conservatory of Music of Castelfranco Veneto in 1993. Concurrently to the music studies he graduated in technology disciplines with the highest honors and distinction, obtaining a scholarship, defending the thesis entitled "Study on the implementation of algorithms for the melodic operators in the symbolic text segmentation and conjoint evaluation of musical entropy". His dual formation, in Information Technology and music, drives him into carrying out research activities on the relation between Music and Mathematics. The development of education-related technologies draw him to focus his attention on the innovations of information technology associated to musical programming languages and to attend a Post-Graduate Master's Degree on E-Learning (E-Learning: methods, techniques and applications) at the University Tor Vergata of Rome, graduating from it with the highest marks with the thesis "Learning and new technologies". His research activity continues within the framework of computer-aided musical analysis, publishing articles and holding national and international conferences and seminars on "Music and new technologies". He combines his research and IT consultant activity with the position of Music informatics Professor at Music Academies and Conservatories and the position of Musical Technologies Teacher in High Schools specializing in Music. 